\title{
The relative importance of genetic and environmental effects for the early stages of thyroid autoimmunity: a study of healthy Danish twins
}

\author{
Pia S Hansen ${ }^{1,2}$, Thomas H Brix ${ }^{1}$, Ivan Iachine ${ }^{3}$, Kirsten O Kyvik ${ }^{2}$ and Laszlo Hegedüs ${ }^{1}$ \\ ${ }^{1}$ Department of Endocrinology and Metabolism, Odense University Hospital, Odense, Denmark and ${ }^{2}$ The Danish Twin Registry, Epidemiology, \\ Institute of Public Health and ${ }^{3}$ Department of Statistics, University of Southern Denmark, JB Winsløwsvej 9B, DK-500O Odense C, Denmark \\ (Correspondence should be addressed to P S Hansen; Email: piaskovhansen@dadlnet.dk)
}

\begin{abstract}
Objective: In euthyroid individuals, autoantibodies to thyroid peroxidase (TPOab) and thyroglobulin (Tgab) are regarded as early markers of thyroid autoimmunity. Family and twin studies suggest that development of thyroid autoantibodies in first-degree relatives of patients with autoimmune thyroid disease is under genetic influence. We aimed to estimate the relative importance of genetic and environmental effects for the presence of thyroid autoantibodies in euthyroid subjects.

Methods: A representative sample of healthy twin pairs was identified through the Danish Twin Registry; 1372 individuals, divided into 283 monozygotic (MZ), 285 dizygotic same sex (DZ), and 118 opposite sex twin pairs were investigated. Serum TPOab and serum Tgab were measured. Probandwise concordance and intraclass correlations were calculated, and quantitative genetic modelling was performed.

Results: Probandwise concordance and intraclass correlations were consistently higher for MZ than for DZ twin pairs indicating genetic influence. Genetic components (with 95\% confidence intervals) accounted for $73 \%(46-89 \%)$ of the liability of being thyroid antibody positive. Adjusting for covariates (age, TSH and others), the estimate for genetic influence on serum TPOab concentrations was $61 \%(49-70 \%)$ in males and $72 \%(64-79 \%)$ in females. For serum Tgab concentrations, the estimates were $39 \%(24-51 \%)$ and $75 \%(66-81 \%)$ respectively.

Conclusions: Early markers of thyroid autoimmunity appear to be under strong genetic influence. The analyses suggest that it is the same set of genes that operate in males and females. However, complex mechanisms such as dominance and/or epistasis may be involved.
\end{abstract}

European Journal of Endocrinology 154 29-38

\section{Introduction}

Autoimmune thyroid diseases (AITD) comprise Graves' disease and Hashimoto's thyroiditis. These conditions share distinct immunological features such as autoreactivity against the key thyroid autoantigens thyroglobulin and thyroid peroxidase $(1,2)$. We have previously established that a strong genetic component exists for Graves' disease (3) as well as Hashimoto's thyroiditis (4). The presence of autoantibodies to thyroid peroxidase (TPOab) and thyroglobulin (Tgab) in euthyroid subjects might represent an early stage in the pathogenesis of overt AITD (1, 5). According to the endophenotypic approach, it might be useful to decompose a complex phenotype into a set of variables that might represent more basic processes (6). A phenotypic anchor point such as the presence of thyroid autoantibodies could be a valuable first step towards defining disease genes.

Family studies have demonstrated an aggregation of thyroid autoantibodies in the relatives of patients with overt thyroid disease $(7-10)$, and it has been proposed that the tendency for thyroid autoantibody production is genetically determined $(7-12)$. However, the hypothesis of simple genetic transmission has been questioned in favour of multifactorial inheritance $(9,13)$. Moreover, family studies cannot determine whether the observed familial aggregation is due to shared genes or a shared environment. Using twins, we have very recently shown that the phenomenon of familial clustering of thyroid autoantibodies is genetically determined (14). However, being ascertained through a proband with overt AITD, the twins represented a selected study sample (14) and the study did not give any information on the relative impact of genetic and environmental factors in the aetiology of spontaneous thyroid autoantibody production in healthy euthyroid individuals.

The limited twin data available with respect to the presence of thyroid autoantibodies in euthyroid twin individuals are conflicting $(15,16)$. Buchanan et al. (15) suggested a strong environmental influence, whereas Phillips et al. (16) found higher concordance 
rates for thyroid autoantibodies in monozygotic (MZ) than in dizygotic (DZ) twins, indicating a genetic influence. However, both studies were small and did not allow precise estimates of the impact of genetic and environmental factors.

The presence of thyroid autoantibodies is associated with gender $(5,9,17,18)$ and increasing age $(5,18$, 19). An influence of iodine intake is suggested - at least in the older age groups $(17,18)$. In euthyroid subjects, TPOab are correlated with increasing thyrotrophin (TSH) levels (19), whereas tobacco smoking and oestrogen use are without influence on TPOab levels (19). Whether factors such as infectious agents $(20,21)$ and stress $(21)$ are involved is under debate.

In this study, we estimate the relative importance of genetic and environmental effects for the presence of thyroid autoantibodies in a large population-based sample of healthy euthyroid twins. Furthermore, the relative contribution of a number of possible environmental factors involved in antibody production is clarified.

\section{Subjects and methods}

\section{Subjects}

The present study is part of a nationwide project (GEMINAKAR) investigating the relative influence of genetic and environmental factors on a variety of different traits among Danish twins. Based on a questionnaire survey concerning physical health and health-related behaviour performed in 1994, a representative sample of complete twin pairs was recruited from the population-based Danish Twin Registry (22). The twins included in the GEMINAKAR study were healthy as reported by themselves, although individuals with chronic diseases such as low back pain, migraine etc. were included in the study population. With the exception of oestrogens, including contraceptives, no twins were taking medicine known to affect the pituitarythyroid axis or thyroid size. In order to get an equal distribution of twin pairs, sampling was stratified according to age, sex and zygosity.

The examinations were running in parallel, throughout the year, at The Danish Twin Registry in Odense and at The Institute of Preventive Medicine in Copenhagen from 1997 to 2000. The twins in a pair were examined on the same day. All twins with at least one partner living in the western part of Denmark were examined in Odense, whereas all those where both partners were living in the eastern part of Denmark were examined in Copenhagen. With the exception of 39 twin pairs, both twins in a pair lived in the same geographical region of Denmark. Denmark is regarded as an area with mild to moderate iodine deficiency (18). Blood samples were drawn between 0800 and $0900 \mathrm{~h}$ after a $12 \mathrm{~h}$ fast. A clinical examination was performed and the twins filled in health-related questionnaires including questions regarding thyroid disease, smoking habits and medicine intake.

$\mathrm{TSH}$, serum free thyroxine (free T4), serum free triiodothyronine (free T3) and serum TPOab and Tgab were measured.

In all, 1512 individuals (756 twin pairs) were examined. However, due to a missing blood sample (39 persons in 20 twin pairs) and self-reported thyroid disease (32 persons in 28 twin pairs) 48 twin pairs were excluded. Moreover, three subjects had overt biochemical hyperthyroidism defined as decreased serum TSH (serum TSH $<0.3 \mathrm{mU} / \mathrm{l}$ ) and increased serum free T4 (serum free T4 $>17.7 \mathrm{pmol} / \mathrm{l}$ ) and/or increased serum free T3 (serum free T3 $>7.4 \mathrm{pmol} / \mathrm{l}$ ). Additionally, 16 individuals had overt hypothyroidism defined as serum $\mathrm{TSH}>4.0 \mathrm{mU} / \mathrm{l}$ and serum free $\mathrm{T} 4$ $<9.9 \mathrm{pmol} / \mathrm{l}$. These individuals and their co-twins were also excluded, leaving 1380 healthy individuals or 690 twin pairs. A single opposite sex (OS) twin pair was excluded because one of the twins had a missing serum Tgab value. Thus, 284 MZ, 286 DZ and 119 OS twin pairs were included using dichotomized data. Analysing serum TPOab and Tgab as continuous data, two subjects were regarded as outliers due to TPOab values above $3000 \mathrm{kIU} / \mathrm{ml}$, and these two twins and their co-twins were excluded. Finally, due to a missing serum T3 value one twin pair was excluded, leaving 686 twin pairs distributed into 283 MZ, 285 DZ and 118 OS twin pairs. Mean ages of the MZ, DZ and OS twins were 37.1 years (S.D. 10.9), 36.9 years (S.D. 10.4) and 37.1 years (S.D. 11.6) respectively. Written informed consent was obtained from all participants and the study was approved by all regional Danish Scientific-Ethical Committees (Case File 97/25 PMC).

\section{Assays}

Serum TSH was measured using a time-resolved fluoroimmunometric assay (AutoDELFIA hTSH Ultra Kit; Perkin Elmer/Wallac, Turku, Finland). Reference range is $0.30-4.00 \mathrm{mU} / \mathrm{l}$. Serum free T4 and serum free T3 were determined using the AutoDELFIA FT4 and FT3 (Perkin Elmer/Wallac) respectively. For free $\mathrm{T} 4$ the reference range is $9.9-17.7 \mathrm{pmol} / \mathrm{l}$, and for free T3 it is $4.3-7.4 \mathrm{pmol} / \mathrm{l}$. TPOab and Tgab were measured by solid-phase, two step, time-resolved fluoroimmunoassays (AutoDELFIA TPOab kit and hTgab kit respectively; Perkin Elmer/Wallac). Intra- and interassay coefficients of variation for TPOab and Tgab were between 3.2 and $8.4 \%$ and 3.8 and $10.1 \%$ respectively, in the range of $50-155 \mathrm{kIU} / \mathrm{ml}$. Twin pairs were analysed within the same run. All the serum samples were analysed at the same laboratory in Odense. Zygosity was established by analysis of nine highly polymorphic restriction fragment length polymorphisms and microsatellite markers widely scattered through 
the genome with an Applied Biosystems AmpFISTR Profiles Plus kit (Perkin Elmer) (23).

\section{Statistical analyses}

Phenotype definitions Analyses were performed with dichotomized data as well as continuous data. Using dichotomized data, a positive thyroid antibody status was defined as a positive TPOab and/or Tgab value. As recommended by the Perkin Elmer Corporation, values above $60 \mathrm{kIU} / \mathrm{ml}$ were regarded as positive for TPOab as well as for Tgab. In addition, the analyses were performed using cut-off values of 20 and $100 \mathrm{kIU} / \mathrm{ml}$. Using continuous data, TPOab and Tgab levels were analysed separately. The frequency distribution of serum TPOab and Tgab were skewed and after descriptive analyses but prior to twin analyses, the data were transformed using the natural logarithm.

Descriptive analyses The potential effects of gender, age, serum TSH, serum free T4, serum free T3, examination place and cigarette smoking (non-smokers were subjects who had never smoked, whereas smokers were defined as former or current smokers), on thyroid antibody status and serum TPOab and Tgab levels were analysed using multivariate logistic regression analysis with cluster option and backward stepwise multivariate linear regression analysis (with a limit for entry into the model of 0.05) with cluster option respectively. The equality of means and variances across zygosity was tested using Mx and likelihood ratio tests (24) as well as a clustered version of Levene's test for homogeneity of variances (25).

Twin analyses The classic twin study is based on the assumption that MZ twins are genetically identical, and therefore differences between them are solely due to the environment. DZ twins share on average 50\% of their segregating genes, and therefore differences between them are due to a combination of environmental and genetic factors $(24,26)$. If there is a substantial genetic component in the aetiology of the phenotype, a greater phenotypic similarity in MZ than in DZ twins is to be expected. Considering thyroid antibody status (dichotomized data), the similarity in MZ and DZ twins was assessed by probandwise concordance and tetrachoric correlations. Considering serum TPOab and serum Tgab as continuous data, Pearson's and intraclass correlations were used.

Probandwise concordance and tetrachoric correIations (dichotomized data) The probandwise concordance was defined as the proportion of affected co-twins of probands. Probandwise concordance expresses the risk that a twin is affected given an affected co-twin, and it is directly comparable with disease risk rates in the background population (27). The calculation of tetrachoric correlations is based on the assumption that there is an underlying normal distribution of liability to thyroid antibody status $(24,28)$. The trait becomes manifest when an individual exceeds a given threshold on the liability distribution (24). The threshold reflects the prevalence of the trait. Using $\mathrm{Mx}$, the effects of age, gender, InTSH and serum free T3 were incorporated in the model as covariates by assuming a linear dependence of the thresholds on the covariates. The results were compared with a model without adjustment. The difference in correlations between MZ and DZ twin pairs was assessed with a likelihood ratio test (24).

Correlations for serum TPOab and Tgab levels (continuous data) Pearson's correlations were computed separately, for the five groups of twins (MZmale, DZ-male, MZ-female, DZ-female, OS). In addition, adjusted intraclass correlations for serum TPOab and serum Tgab concentrations were calculated for MZ and DZ same-sex twins. The adjustment for covariates was performed using the residuals resulting from the multivariate regression analysis described in descriptive analyses. For serum TPOab the covariates included age, InTSH and serum free T3. For serum Tgab, the adjustment included age, lnTSH, serum free T3 and smoking.

Model-fitting procedure Structural equation modelling was used to estimate the magnitude of the genetic and environmental effects on the liability of thyroid antibody status as well as on serum concentrations of TPO and Tgab. The structural equation modelling approach is based on familial relations and was carried out using maximum likelihood methods in the software programme Mx. The observed phenotypic variance is decomposed into genetic and environmental contributions (24). The genetic variance is further subdivided into an additive (A) component and a dominance (D) component. The environmental contribution is divided into a shared/common environmental component (C) and a unique (E) environmental component. The heritability is defined as the proportion of the total variance attributable to total genetic variance (i.e. additive and dominance components) $(24,26)$.

$\mathrm{C}$ and $\mathrm{D}$ are confounded and cannot be estimated simultaneously in a twin study of MZ and DZ twins reared together $(24,26,28)$. Reduction to nested submodels was attempted and the most parsimonious model in the analyses was selected (24). For comparison among nested models, we used a likelihood ratio test. The difference in $2 \times \log$ likelihood between a full model and that of a submodel $(\Delta 2 \mathrm{LL})$ is distributed as a chi-square statistic, with the degrees of freedom equal to the difference in the degrees of freedom of the models being compared (24). The selection of the best-fitting model was carried out using the Akaike Information Criterion (AIC), which is based on a balance between goodness of fit and parsimony (24). AIC corresponds to $\Delta 2 \mathrm{LL}-2 \times \Delta$ df. Models with the lowest AIC were preferred. Models were fitted to 
the raw data using raw data methods in Mx $(29,30)$. The effects of specific covariates (as specified earlier) were incorporated in the analyses. According to standard biometric practice $(24,28)$, we assumed equal environment for MZ and DZ twins, no epistasis (genegene interaction), and no gene-environment interaction or correlation. The observed gender differences were examined including the OS twins in the model-fitting analyses of Tgab and TPOab levels. Including the OS twins allows us (i) to obtain a more precise estimate of the magnitude of genetic and environmental effects in males and females and (ii) to determine whether or not it is the same set of genes that operate in males and females. Specific information on sex differences derives from the correlation in OS twins. If the same set of genes act in males and females, the genetic correlation between males and females in OS twins is the same as in DZ twin pairs. Therefore, the model in which the genetic correlation between males and females in the OS twins was estimated freely, was compared with a model in which this correlation was fixed to be the same as in DZ twins, using chi-square statistic.

\section{Statistical software}

The descriptive statistical analyses were carried out using STATA. Level of significance was set to 0.05. Univariate quantitative genetic modelling was carried out using Mx (30).

\section{Results}

\section{Descriptive analyses}

Thyroid antibody status (dichotomized data) The total number of subjects with thyroid antibodies was $98(7.1 \%)$, compared with $174(12.6 \%)$ and 73 $(5.3 \%)$ using cut-off values at 20 and $100 \mathrm{kIU} / \mathrm{ml}$ respectively. A highly significant influence of age, gender, serum TSH and serum free T3 was found (Table 1). The prevalence of thyroid antibodies across zygosity groups is given in Table 2 . Within the OS twin pairs a large difference in prevalence was found.

\section{Analysis of serum TPOab and Tgab concentrations (continuous data) No significant difference in variance} was found across zygosity for TPOab concentrations; however, a significant difference in variance between MZ and DZ twin pairs was found for Tgab concentrations, which could not be reduced by standard transformations or by adjustment of the data.

Using multivariate regression analyses, for serum TPOab concentrations, a highly significant influence of age (with 95\% confidence intervals (CIs)): $\beta_{\text {age }}=0.013 \quad(0.007-0.018, \quad P<0.001), \quad$ gender: $\beta_{\text {gender }}=-0.16 \quad(-0.28$ to $-0.04, \quad P=0.011)$, serum TSH: $\beta_{\operatorname{lnTSH}}=0.30(0.16-0.43, P<0.001)$, and serum free T3: $\beta_{\text {FreeT3 }}=-0.09 \quad(-0.16$ to $-0.03, P=0.004$ ) was found. Serum free T4, examination place and smoking had no significant influence.

For serum Tgab levels we found significant influence of age: $\beta_{\text {age }}=0.008(0.003-0.01, P=0.001)$, gender: $\beta_{\text {gender }}=-0.11(-0.20$ to $-0.01, P=0.034)$, InTSH: $\beta_{\text {InTSH }}=0.09(0.007-0.17, P=0.033)$, serum free T3 level: $\beta_{\text {FreeT3 }}=-0.11(-0.16$ to $0.05, P<0.001)$ and cigarette smoking: $\beta_{\text {Smoking }}=-0.17$ ( -0.26 to -0.08 , $P<0.001)$. Serum free T4 level and examination place had no significant influence.

\section{Twin analysis}

Probandwise concordance and tetrachoric correlations The probandwise concordances and the unadjusted as well as the adjusted tetrachoric correlations for thyroid antibody status are shown in Table 3. The concordance was higher in MZ than in DZ twin pairs. A pattern with high tetrachoric correlations in MZ twins as compared with DZ twins was found. Gender adjustment had the largest influence, whereas only minimal effect was demonstrated with additional adjustment for age, lnTSH and serum free

Table 1 Number of subjects and descriptive characteristics according to thyroid antibody status using a cut-off at $60 \mathrm{U} / \mathrm{ml}$.

\begin{tabular}{|c|c|c|c|}
\hline & Negative thyroid antibody status & Positive thyroid antibody status & $P$-value \\
\hline Total (number of subjects) & 1280 & 98 & \\
\hline \multicolumn{4}{|l|}{ Gender } \\
\hline Female (number of subjects) & 617 & 74 & \multirow[t]{2}{*}{$<0.001$} \\
\hline Male (number of subjects) & 663 & 24 & \\
\hline Age (years) & 36.7 (S.D. 10.8) & 40.9 (S.D. 10.0) & $0.010^{*}$ \\
\hline Serum TSH (mU/l) & 1.71 (S.D. 0.87 ) & 2.13 (S.D. 1.26) & $0.011 *$ \\
\hline Serum free T4 $(\mathrm{pmol} / \mathrm{l})$ & 12.85 (S.D. 1.64) & 12.53 (S.D. 1.63) & $0.126^{\star}$ \\
\hline Serum free T3 (pmol/l) & 6.23 (S.D. 0.89) & 5.70 (S.D. 0.73) & $0.001 *$ \\
\hline \multicolumn{4}{|l|}{ Smoking } \\
\hline Non-smokers (number of subjects) & 641 & 45 & \multirow[t]{2}{*}{0.427} \\
\hline Smokers (number of subjects) & 639 & 53 & \\
\hline
\end{tabular}

*A two-sample Wilcoxon rank-sum (Mann-Whitney) test with Brunner's adjustment for clustering within the twin pair was used to test difference between the groups taking the dependence of the twins into account. 
Table 2 Prevalence of thyroid antibody positivity, and correlations for TPOab and Tgab concentration across zygosity.

\begin{tabular}{|c|c|c|c|c|c|}
\hline \multirow[b]{2}{*}{$\begin{array}{l}\text { Zygosity } \\
\text { group }\end{array}$} & \multicolumn{2}{|r|}{ Prevalence } & \multicolumn{3}{|c|}{ Pearson's correlation } \\
\hline & $n^{\#}$ & $\begin{array}{c}\text { Thyroid antibody } \\
\text { positivity (\%) }\end{array}$ & $n^{\#}$ & InTPO & InTgab \\
\hline MZM & 142 & 2.13 & 141 & 0.5012 & 0.3395 \\
\hline DZM & 142 & 2.46 & 142 & 0.2711 & 0.2673 \\
\hline MZF & 142 & 8.10 & 142 & 0.6901 & 0.5897 \\
\hline DZF & 144 & 11.19 & 143 & 0.0907 & 0.1504 \\
\hline OS & 119 & 11.02 & 118 & 0.3070 & 0.2015 \\
\hline Male & & 6.78 & & & \\
\hline Female & & 15.25 & & & \\
\hline
\end{tabular}

$\mathrm{MZM}=$ monozygotic males; DZM = dizygotic males; $\mathrm{MZF}=$ monozygotic females; DZF = dizygotic females and OS = opposite sex.

\#Number of twin pairs. The discrepancy between number of paris in the dichotomous and the continous data analysis is explained in the text.

T3 (data not shown). Using low and high cut-off values of 20 and $100 \mathrm{kIU} / \mathrm{ml}$ respectively, for TPOab as well as for Tgab, did not significantly change the overall findings (data not shown).

Pearson's and intraclass correlations Pearson's correlations are given in Table 2. The MZ correlations are markedly higher as compared with DZ correlations, especially in females. Figure 1 is a scatterplot of the transformed and adjusted values of serum TPOab and Tgab concentrations for the $283 \mathrm{MZ}$ twin pairs and 285 DZ same-sex twin pairs. Furthermore, the adjusted intraclass correlations are presented in Figure 1. The correlation coefficients were substantially higher for $\mathrm{MZ}$ pairs than for DZ pairs, both for TPOab

Table 3 Number of twin pairs, probandwise concordance and tetrachoric correlations according to zygosity and phenotype.

\begin{tabular}{|c|c|c|c|c|}
\hline \multirow{4}{*}{$\begin{array}{l}\text { Number of twin pairs } \\
\text { MZ } \\
\text { DZ }\end{array}$} & \multicolumn{3}{|c|}{$\begin{array}{c}\text { Thyroid } \\
\text { antibody status }\end{array}$} & \multirow[t]{4}{*}{$P$-value } \\
\hline & $+/+$ & $+1-$ & $-1-$ & \\
\hline & 7 & 17 & 260 & \\
\hline \multirow{2}{*}{\multicolumn{5}{|c|}{ Probandwise concordance ${ }^{a}$}} \\
\hline & & & & \\
\hline $\mathrm{MZ}$ & \multirow{2}{*}{\multicolumn{3}{|c|}{$\begin{array}{l}0.45(0.22-0.67) \\
0.15(0.00-0.33)\end{array}$}} & \multirow[t]{2}{*}{0.022} \\
\hline $\mathrm{DZ}$ & & & & \\
\hline \multicolumn{5}{|c|}{ Tetrachoric correlation (unadjusted) $^{\mathrm{b}}$} \\
\hline $\mathrm{MZ}$ & \multirow{2}{*}{\multicolumn{3}{|c|}{$\begin{array}{l}0.77(0.51-0.91) \\
0.25(-0.11-0.57)\end{array}$}} & \multirow[t]{2}{*}{0.012} \\
\hline DZ & & & & \\
\hline \multicolumn{5}{|c|}{ Tetrachoric correlation (adjusted $\left.{ }^{c}\right)^{b}$} \\
\hline$M Z$ & \multirow{2}{*}{\multicolumn{3}{|c|}{$\begin{array}{l}0.72(0.44-0.89) \\
0.19(-0.20-0.55)\end{array}$}} & 0.020 \\
\hline $\mathrm{DZ}$ & & & & \\
\hline
\end{tabular}

MZ: monozygotic; DZ: dizygotic same sex. $+/+$ and $-/-$ concordant pairs. $+/-$ : discordant pairs. $95 \%$ Cls are given in parentheses. Positive thyroid antibody status was defined as a TPOab and/or Tgab value above $60 \mathrm{kIU} / \mathrm{ml}$. Performing the analyses with a cut-off value of either 20 or $100 \mathrm{kJU} / \mathrm{ml}$ did not significantly alter the findings.

${ }^{a} \mathrm{~A}$ bootstrap method was used testing the difference in probandwise concordance (one sided)

${ }^{\mathrm{b}} \mathrm{A}$ likelihood ratio test was used testing the difference in tetrachoric correlations between zygosity groups.

${ }^{c}$ Adjustment for age, gender, InTSH and serum free T3.
$\left(\mathrm{r}_{\mathrm{MZ}}=0.65, \mathrm{r}_{\mathrm{DZ}}=0.13, P<0.0001\right)$ and for Tgab $\left(\mathrm{r}_{\mathrm{MZ}}=0.48, \mathrm{r}_{\mathrm{DZ}}=0.18, P<0.0001\right)$.

Biometric modelling (Table 4) The pattern of correlations, with much larger MZ correlations than DZ correlations, suggests the presence of dominance, therefore the ADE model was chosen. Subsequently, reduction to nested submodels was attempted.

Considering thyroid antibody status, adjusting for gender, age, lnTSH and serum free T3, the best-fitting model was a DE model, including dominance and unique environmental effects. Genetic factors explained $73 \%$ (95\% CI: $46-89 \%)$ of the liability to be thyroid autoantibody positive - this is the heritability estimate. The remaining $27 \%$ (95\% CI: $11-54 \%$ ) was attributable to unique environmental factors. In contrast, in the unadjusted model, genetic factors explained $77 \%$ (95\% CI: $53-91 \%$ ) of the liability (data not shown). Using thyroid antibody levels of either 20 or $100 \mathrm{kIU} / \mathrm{ml}$ as cut-off values did not significantly change these results.

The results of model-fitting analyses for serum TPOab and Tgab concentrations are given in Table 4. The models that in the best way explain our data are DE models. Considering serum TPOab concentration as a continuous variable adjusting for age, gender, $\operatorname{lnTSH}$ and serum free T3, genetic influences explain $61 \%$ (95\% CI: $49-70 \%)$ of the variation for males and $72 \%$ (95\% CI: $64-78 \%$ ) for females. Constraining the genetic and environmental estimates to be equal for males and females in TPOab levels did not cause a significant deterioration in model fit $(P=0.07)$, indicating that the heritability estimates are the same for males and females.

For serum Tgab concentration, adjustment included age, gender, InTSH, serum free T3 and smoking, and the genetic influence was responsible for 39\% $(95 \%$ CI: $24-51 \%$ ) in males and 75\% (95\% CI: 66-81\%) in females. For serum Tgab levels, constraining the estimates to equality across gender provided a significantly worse fit $(P<0.001)$; therefore this model was rejected. This suggests differences in the magnitude of the relative contribution of genetic and environmental effects across gender. Yet, fixing the genetic correlation in OS twin pairs to be the same as in DZ twins for TPOab as well as for Tgab levels did not result in a significantly worse fit, implying that it might be the same set of genes that act in males and females for both phenotypes. In general, adjusting for covariates had negligible effect on the heritability estimates.

\section{Discussion}

A strong genetic influence on the presence of antibodies against TPO and $\mathrm{Tg}$ in healthy, euthyroid subjects was demonstrated. Such antibodies are the common denominator of human thyroid autoimmunity, 

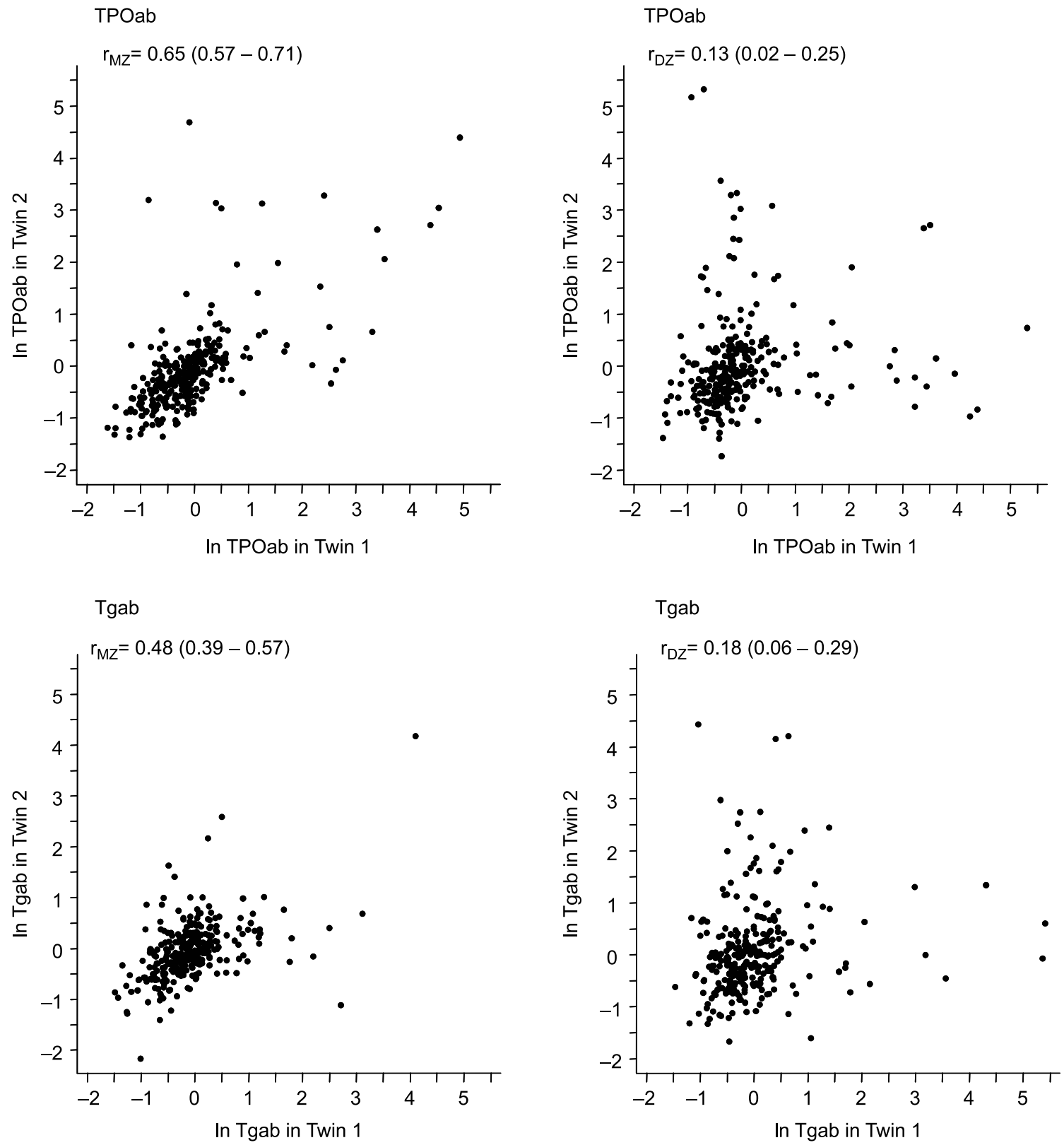

Figure 1 Scatterplots and intraclass correlations of the transformed and adjusted serum TPOab and Tgab concentrations according to zygosity. Number of twin pairs and $95 \% \mathrm{Cls}$ are given in parentheses.

encompassing Graves' disease and Hashimoto's thyroiditis. Overt AITD is affected by a variety of genetic and environmental influences $(1-4,31)$. It is assumed that the thyroid autoimmune process is a continuum, where the presence of thyroid antibodies in healthy euthyroid individuals represents an early subclinical stage of disease $(1,32)$. The exact natural history of AITD remains obscure. A recent study revealed that TPOab are detectable in serum of nearly all euthyroid individuals (33). Whether these low TPOab concentrations represent natural self-reactive antibodies or are the detectable starting point in the human autoimmune process is at present unknown $(33,34)$.

In cross-sectional twin studies, the magnitude of genetic influence seems to be the same in different stages of the autoimmune process comprising both overt Graves' disease $(3,31)$ and overt Hashimoto's thyroiditis (4), as well as their subclinical stages. A previous study, using very low cut-off values, found higher MZ concordance as compared with DZ concordance for TPOab as well as for Tgab (16). In the present study, the values for probandwise concordance are lower, but interestingly, 
Table 4 Results of model-fitting analyses" ${ }^{\#}$. Best-fitting model is highlighted in bold; 95\% Cls are given in parentheses.

\begin{tabular}{|c|c|c|c|c|c|c|c|c|c|c|c|c|}
\hline \multirow[b]{3}{*}{ Model } & \multicolumn{3}{|c|}{ Males } & \multicolumn{3}{|c|}{ Females } & \multirow{3}{*}{$\begin{array}{c}\begin{array}{c}\text { Goodness of } \\
\text { fit tests }\end{array} \\
-2 L L^{b}\end{array}$} & \multirow{2}{*}{\multicolumn{5}{|c|}{$\begin{array}{l}\text { Comparisons of nested } \\
\text { submodels }\end{array}$}} \\
\hline & \multicolumn{2}{|c|}{ Genetic components } & \multirow{2}{*}{$\frac{\text { Environmental component }}{\mathrm{E}}$} & \multicolumn{2}{|c|}{ Genetic components } & \multirow{2}{*}{$\frac{\text { Environmental component }}{\mathrm{E}}$} & & & & & & \\
\hline & A & $\mathrm{D}$ & & A & $\mathrm{D}$ & & & Vs model & $\Delta 2 L^{c}{ }^{c}$ & $\Delta d f^{d}$ & AIC & $P^{\mathrm{e}}$ \\
\hline \multicolumn{13}{|l|}{ TPOab $^{\mathrm{a}}$} \\
\hline ADE & $0.35(0.00-0.67)$ & $0.25(0.00-0.68)$ & $0.40(0.30-0.53)$ & $0.00(0.00-0.39)$ & $0.72(0.32-0.78)$ & $0.28(0.22-0.36)$ & 3425.01 & - & - & - & - & - \\
\hline $\mathrm{AE}$ & $0.08(0.03-0.83)$ & - & $0.92(0.17-0.97)$ & $0.69(0.23-0.88)$ & - & $0.31(0.12-0.77)$ & 3476.70 & 1 & 51.682 & 3 & 45.682 & 0.000 \\
\hline$D^{*}$ & - & $0.61(0.49-0.70)$ & $0.39(0.30-0.51)$ & - & $0.72(0.64-0.78)$ & $0.28(0.22-0.36)$ & 3426.42 & 1 & 1.402 & 3 & -4.598 & 0.705 \\
\hline $\mathrm{E}$ & - & - & - & - & - & 1 & 3580.77 & 1 & 155.76 & 6 & 143.76 & 0.000 \\
\hline \multicolumn{13}{|l|}{$\operatorname{Tgab}^{\mathrm{a}}$} \\
\hline ADE & $0.39(0.00-0.50)$ & $0.00(0.00-0.41)$ & $0.61(0.50-0.75)$ & $0.00(0.00-0.27)$ & $0.75(0.46-0.81)$ & $0.25(0.19-0.34)$ & 2919.98 & - & - & - & - & - \\
\hline $\mathrm{AE}$ & $0.39(0.25-0.50)$ & - & $0.61(0.50-0.75)$ & $0.00(0.00-0.00)$ & - & $1.00(0.99-1.00)$ & 3001.98 & 5 & 81.418 & 3 & 75.42 & 0.000 \\
\hline$D^{*}$ & - & $0.39(0.24-0.51)$ & $0.61(0.49-0.76)$ & - & $0.75(0.66-0.81)$ & $0.25(0.19-0.34)$ & 2923.73 & 5 & 3.747 & 3 & -2.253 & 0.290 \\
\hline $\mathrm{E}$ & - & - & - & - & - & 1 & 3027.96 & 5 & 107.98 & 6 & 95.98 & 0.000 \\
\hline
\end{tabular}

\# In the analyses, the genetic correlation between males and females in OS pairs is estimated freely.

* The best-fitting model.

a Adjustment for age, InTSH and serum free T3 (and smoking in Tgab).

Minus 2 times log likelihood of data.

The dull model and the submodel.

the submodel.

e A Low P-value indicates a poor fit of the submodel compared to the full model. 
the results did not change using different cut-off values. Moreover, the results were consistent using either categorical or continuous data, and in the latter, thyroid antibody values in the low range are included. However, the particular genetic variation involved in the tendency of having thyroid autoantibodies might not be identical to the variation of the risk of developing overt AITD. The influence of various genes and environmental factors may differ throughout different stages of the disease spectrum. Most probably distinct loci, such as the CTLA-4 gene (35), underlie the continuum of severity with additional modifying genetic or environmental factors which may lead to differential expression of the thyroid autoimmunity $(2,6,21,35)$.

This study as well as several other family and twin studies provides convincing evidence in favour of a strong genetic influence on thyroid autoimmunity. However, relating our results to the results of the existing molecular genetic studies an apparent paradox becomes evident, because the considerable efforts trying to map and identify these AITD susceptibility genes have met limited success $(2,35-37)$. Assuming a continuum of the autoimmune process, we expect at least some of these AITD susceptibility genes to be responsible for the presence of antibodies (35). Several genomic segments exhibiting weak statistical association with disease susceptibility have been identified, but the lack of replication between the various studies is conspicuous $(2,36)$ - especially having the suggested strong genetic influence in mind. The explanations for this apparent paradox are many. First of all, in many of the studies the limiting factors are disease loci with limited effects combined with small sample sizes (38). Furthermore, several combinations of genes within the genome are capable of causing similar or identical clinical endpoints. Finally, complex mechanisms such as epistasis (gene-gene interaction) and gene-environment interaction most likely exist - but are neglected. The precise characterization of a factor's contribution to a complex disease may be difficult, because each factor forms part of a context dependency $(6,39-41)$.

The present study may support the importance of complex mechanisms. Our results were characterized by high MZ correlations combined with very low DZ correlations, especially in females. Furthermore, in model-fitting analyses, the statistically best-fitting model was a DE model. This is not a biologically plausible model $(42,43)$. Several reasons may explain this result. First of all, the power to distinguish between the A and D components is low. Moreover, such results may indicate the presence of complex effects such as epistasis $(39,44,45)$ or competitive sibling interaction $(24,46)$. We find it unlikely that sibling interaction effects are of importance in these biological phenotypes. However, our study cannot resolve the contribution of dominance and epistasis to non-additive effects (45), and it is possible that the estimate for non-additivity may involve epistatic interactions between loci rather than simple dominance interaction within a single locus. We suggest that the estimate of dominance is inflated at the expense of additive genetic variance due to the presence of unmodelled epistatic effects (45). This phenomenon would partly explain the apparent paradox with moderately heritable traits but in which locus-by-locus analyses have not yet detected loci with the predicted genetic effect (43). Epistasis reduces the overall amount of information available $(39,43,47)$.

Using dichotomized data, the TPOab and Tgab data were combined and we were able to use different cutoff values. However, in this way we 'dichotomized' what is actually a continuous variable, and it may reduce important variation. Yet, analysing TPOab and Tgab as continuous variables did not change the overall picture. A consistently strong genetic influence was found. However, the differences in MZ/DZ correlations were especially marked in females, and within the OS twin pairs the prevalence of thyroid antibodies was higher in females than in males. This indicates interesting gender differences. Under the assumption that the best-fitting model was a DE model for females as well as for males, the analyses suggested differences in the magnitude of the heritability estimate across gender for Tgab levels, but not for TPOab levels. Whether these results reflect differences in the aetiology remains to be established. On the other hand, adding OS twins allowed us to test whether different genetic influences operate in males and females. If the OS correlation is markedly less than the same sex DZ correlation, it can be inferred that sex-specific effects are operating. Nevertheless, this was actually not the case, and the results from model-fitting analyses suggested that it may be the same set of genes acting in males and females for both phenotypes. We tried to control for the effects of distinct risk factors and potential confounders by incorporating the linear effects of these specific covariates in the model (24). In general, adjusting for covariates had negligible effect on the results.

In conclusion, early markers of thyroid autoimmunity appear to be under strong genetic influence. The analyses suggest that it is the same set of genes that operate in males and females. Complex mechanisms such as dominance and/or epistasis (gene-gene interaction) may be involved.

\section{Acknowledgements}

We thank Ole Blaabjerg and Esther Jensen for supervising the biochemical analyses and Claus $\mathrm{H}$ Nielsen for valuable discussions regarding natural self-reactive antibodies. This work was supported by grants from the Foundation of 17-12-1981, the Agnes and Knut Mørk Foundation; the Novo Nordisk Foundation; the Foundation of Medical Research in the County of Funen; 
Else Poulsens Mindelegat; the Foundation of Direktør Jacob Madsen and Hustru Olga Madsen; the Foundation of Johan Boserup and Lise Boserup; the A P Møller and Hustru Chastine McKinney Møllers Foundation; the A P Møller Relief Foundation; and the Clinical Research Institute, Odense University. Perkin Elmer/Wallac, Turku, Finland, kindly provided the kits for determination of TPOab, Tgab, serum TSH, free T4 and free T3.

\section{References}

1 Weetman AP. Determinants of autoimmune thyroid disease. Nature Immunology 20012 769-770.

2 Tomer Y \& Davies TF. Searching for the autoimmune thyroid disease susceptibility genes: from gene mapping to gene function. Endocrine Reviews 200324 694-717.

3 Brix TH, Kyvik KO, Christensen K \& Hegedüs L. Evidence for a major role of heredity in Graves' disease: a population-based study of two Danish twin cohorts. Journal of Clinical Endocrinology and Metabolism 200186 930-934.

4 Brix TH, Kyvik KO \& Hegedüs L. A population-based study of chronic autoimmune hypothyroidism in Danish twins. Journal of Clinical Endocrinology and Metabolism 200085 536-539.

5 Vanderpump MP, Tunbridge WM, French JM, Appleton D, Bates D, Clark F, Grimley EJ, Hasan DM, Rodgers H, Tunbridge F \& Young ET. The incidence of thyroid disorders in the community: a twenty-year follow-up of the Whickham Survey. Clinical Endocrinology 199543 55-68.

6 Schork NJ. Genetics of complex disease: approaches, problems, and solutions. American Journal of Respiratory and Critical Care Medicine 1997156 S103-S109.

7 Hall R, Owen SG \& Smart GA. Evidence for genetic predisposition to formation of thyroid autoantibodies. Lancet 1960 ii 187-188.

8 Evans AW, Woodrow JC, McDougall CD, Chew AR \& Evans RW. Antibodies in the families of thyrotoxic patients. Lancet 1967 i 637-641.

9 Hall R, Dingle PR \& Roberts DF. Thyroid antibodies: a study of first degree relatives. Clinical Genetics 19723 319-324.

10 Phillips D, McLachlan S, Stephenson A, Roberts D, Moffitt S, McDonald D, Ad'Hiah A, Stratton A, Young E \& Clark F. Autosomal dominant transmission of autoantibodies to thyroglobulin and thyroid peroxidase. Journal of Clinical Endocrinology and Metabolism $199070742-746$.

11 Pauls DL, Zakarija M, McKenzie JM \& Egeland JA. Complex segregation analysis of antibodies to thyroid peroxidase in Old Order Amish families. American Journal of Medical Genetics $1993 \mathbf{4 7}$ 375-379.

12 Phillips D, Prentice L, Upadhyaya M, Lunt P, Chamberlain S, Roberts DF, McLachlan S \& Smith BR. Autosomal dominant inheritance of autoantibodies to thyroid peroxidase and thyroglobulin studies in families not selected for autoimmune thyroid disease. Journal of Clinical Endocrinology and Metabolism 199172 973-975.

13 Phillips DI, Shields DC, Dugoujon JM, Prentice L, McGuffin P \& Ree SB. Complex segregation analysis of thyroid autoantibodies: are they inherited as an autosomal dominant trait? Human Heredity 199343 141-146.

14 Brix TH, Hansen PS, Kyvik KO \& Hegedus L. Aggregation of thyroid autoantibodies in first-degree relatives of patients with autoimmune thyroid disease is mainly due to genes: a twin study. Clinical Endocrinology $200460329-334$.

15 Buchanan WW, Boyle JA, Greig WR, McAndrew R, Barr M, Gray KC, Anderson JR \& Goudie RB. Occurrence of autoantibodies in healthy twins. Clinical and Experimental Immunology 19672 $803-811$.

16 Phillips DI, Osmond C, Baird J, Huckle A \& Rees-Smith B. Is birthweight associated with thyroid autoimmunity? A study in twins. Thyroid 200212 377-380.
17 Laurberg P, Pedersen KM, Hreidarsson A, Sigfusson N, Iversen E \& Knudsen PR. Iodine intake and the pattern of thyroid disorders: a comparative epidemiological study of thyroid abnormalities in the elderly in Iceland and in Jutland, Denmark. Journal of Clinical Endocrinology and Metabolism $1998 \mathbf{8 3} 765-769$.

18 Pedersen IB, Knudsen N, Jørgensen T. Perrild H, Ovesen L \& Laurberg P. Thyroid peroxidase and thyroglobulin autoantibodies in a large survey of populations with mild and moderate iodine deficiency. Clinical Endocrinology 200358 36-42.

19 Strieder TG, Prummel MF, Tijssen JG, Endert E \& Wiersinga WM. Risk factors for and prevalence of thyroid disorders in a crosssectional study among healthy female relatives of patients with autoimmune thyroid disease. Clinical Endocrinology 200359 396-401.

20 Strieder TG, Wenzel BE, Prummel MF, Tijssen JG \& Wiersinga WM. Increased prevalence of antibodies to enteropathogenic Yersinia enterocolitica virulence proteins in relatives of patients with autoimmune thyroid disease. Clinical and Experimental Immunology $2003132278-282$.

21 Fountoulakis S \& Tsatsoulis A. On the pathogenesis of autoimmune thyroid disease: a unifying hypothesis. Clinical Endocrinology $200460397-409$.

22 Skytthe A, Kyvik K, Holm NV, Vaupel JW \& Christensen K. The Danish Twin Registry: 127 birth cohorts of twins. Twin Research $20025352-357$.

23 User's Manual. Foster City, CA: The Perkin-Elmer Corporation, 1997.

24 Neale MC, Maes HH. Methodology for Genetic Studies of Twins and Families. Dordrecht, The Netherlands: Kluwer Academic Publishers BV, 2002.

25 Iachine I, Petersen HC \& Kyvik KO. Robust tests for the equality of variances for clustered data. http://www.stat.sdu.dk/publications/ preprints/pp006/IachineEtAl04. pdf 2004.

26 Evans DM, Gillespie NA \& Martin NG. Biometrical genetics. Biological Psychology $20026133-51$.

27 McGue M. When assessing twin concordance, use the probandwise not the pairwise rate. Schizophrenia Bulletin $1992 \mathbf{1 8} 171-176$.

28 Rijsdijk FV \& Sham PC. Analytic approaches to twin data using structural equation models. Briefings in Bioinformatics 20023 119-133.

29 Hopper JL, Green RM, Nowson CA, Young D, Sherwin AJ, Kaymakci B, Larkins RG \& Wark JD. Genetic, common environment, and individual specific components of variance for bone mineral density in 10- to 26-year-old females: a twin study. American Journal of Epidemiology 1998147 17-29.

30 Neale MC, Boker SM, Xie G \& Maes HH. Mx: Statistical Modeling, edn 6. VCU Box 900126, Richmond, VA 23298: Department of Psychiatry, 2002.

31 Brix TH, Christensen K, Holm NV, Harvald B \& Hegedüs L. A population-based study of Graves' disease in Danish twins. Clinical Endocrinology $1998 \mathbf{4 8} 397-400$.

32 McLachlan SM \& Rapoport B. Autoimmune response to the thyroid in humans: thyroid peroxidase - the common autoantigenic denominator. International Reviews of Immunology 200019 $587-618$.

33 Zophel K, Saller B, Wunderlich G, Gruning T, Koch R, Wilde J, Mann K \& Franke WG. Autoantibodies to thyroperoxidase $(\mathrm{TPOAb})$ in a large population of euthyroid subjects: implications for the definition of TPOAb reference intervals. Clinical Laboratory $200349591-600$.

34 Nielsen CH, Leslie RG, Jepsen BS, Kazatchkine MD, Kaveri SV \& Fischer E. Natural autoantibodies and complement promote the uptake of a self antigen, human thyroglobulin, by B cells and the proliferation of thyroglobulin-reactive $\mathrm{CD} 4(+) \mathrm{T}$ cells in healthy individuals. European Journal of Immunology 200131 2660-2668.

35 Tomer Y, Greenberg DA, Barbesino G, Concepcion E \& Davies TF. CTLA-4 and not CD28 is a susceptibility gene for thyroid autoantibody production. Journal of Clinical Endocrinology and Metabolism 200186 1687-1693. 
36 Vaidya B, Kendall-Taylor P \& Pearce SH. The genetics of autoimmune thyroid disease. Journal of Clinical Endocrinology and Metabolism 200287 5385-5397.

37 Tomer Y, Barbesino G, Greenberg DA, Concepcion E \& Davies TF Mapping the major susceptibility loci for familial Graves' and Hashimoto's diseases: evidence for genetic heterogeneity and gene interactions. Journal of Clinical Endocrinology and Metabolism $1999 \mathbf{8 4}$ 4656-4664.

38 Broeckel U \& Schork NJ. Identifying genes and genetic variation underlying human diseases and complex phenotypes via recombination mapping. Journal of Physiology 2004 554 40-45.

39 Purcell S \& Sham PC. Epistasis in quantitative trait locus linkage analysis: interaction or main effect? Behavior Genetics 200434 143-152.

40 Wandstrat AE \& Wakeland EK. The genetics of complex autoimmune diseases: non-MHC susceptibility genes. Nature Immunology $20012802-809$.

41 Frankel WN \& Schork NJ. Who's afraid of epistasis? Nature Genetics $1996 \mathbf{1 4} 371-373$.

42 Posthuma D, Beem AL, De Geus EJ, van Baal GC, von Hjelmborg JB, Iachine I \& Boomsma DI. Theory and practice in quantitative genetics. Twin Research $20036361-376$.
43 Culverhouse R, Suarez BK, Lin J \& Reich T. A perspective on epistasis: limits of models displaying no main effect. American Journal of Human Genetics $2002 \mathbf{7 0} 461-471$.

44 Eaves LJ. Dominance alone is not enough. Behavior Genetics 1988 $1827-33$.

45 Eaves LJ, Heath AC, Neale MC, Hewitt JK \& Martin NG. Sex differences and non-additivity in the effects of genes on personality. Twin Research 19981 131-137.

46 Rietveld MJ, Posthuma D, Dolan CV \& Boomsma DL. ADHD: sibling interaction or dominance: an evaluation of statistical power. Behavior Genetics 200333 247-255.

47 Eaves LJ. Effect of genetic architecture on the power of human linkage studies to resolve the contribution of quantitative trait loci. Heredity 199472 175-192.

Received 12 July 2005

Accepted 26 September 2005 